\title{
Bacteroides melaninogenicus subsp. macacae, a New Subspecies from Monkey Periodontopathic Indigenous Microflora
}

\author{
JØRGEN SLOTS AND ROBERT J. GENCO \\ Department of Oral Biology and Periodontal Disease Clinical Research Center, State University of New \\ York at Buffalo, Buffalo, New York 14226
}

\begin{abstract}
The name Bacteroides melaninogenicus subsp. macacae is proposed for a subspecies to accommodate strains of gram-negative, anaerobic, catalase-producing rods which produce black colonies on blood agar plates. The organisms weakly ferment galactose, glucose, lactose, and mannose and exhibit no fermentation of 24 other carbohydrates. The metabolic acid end products formed in peptoneyeast extract-glucose broth cultures include acetic, propionic, isobutyric, butyric, isovaleric, and succinic acids. The organisms utilize pyruvate, digest gelatin, and produce indole and hydrogen sulfide. B. melaninogenicus subsp. macacae appears to be serologically distinct from $B$. asaccharolyticus, $B$. melaninogenicus subsp. levii, $B$. melaninogenicus subsp. intermedius, and $B$. melaninogenicus subsp. melaninogenicus. The type strain of this new subspecies is ATCC 33141.
\end{abstract}

Nonhuman primate models are commonly used in periodontal disease research (1). During studies of experimental periodontitis in stumptailed macaques (Macaca arctoides), our laboratory repeatedly isolated a large number of previously undescribed Bacteroides melaninogenicus strains.

This paper reports on the biochemical and immunological properties of these strains and contains a proposal that the organisms be classified as a distinct subspecies of $B$. melaninogenicus. A study on the prevalence of this organism in relationship to monkey periodontal disease appears elsewhere (7).

\section{MATERIALS AND METHODS}

Bacterial strains. Six strains (MD1-17, 7728-L6C, 7728-R6D, 7511-L6C, 7511-L6D, and 7511-R6B) which were isolated from five periodontal pockets in three $M$. arctoides females were studied. The isolation and preliminary characterization followed procedures previously described (7). The cultures were maintained on Trypticase soy agar (BBL Microbiology Systems) supplemented with $10 \%$ rabbit blood, $0.0005 \%$ hemin, and $0.00005 \%$ menadione (TSB plates). Cultures were incubated at $37^{\circ} \mathrm{C}$ in an anaerobic chamber (Coy Manufacturing Co., Ann Arbor, Mich.) with 85\% Ar, 10\% $\mathrm{H}_{2}$, and $5 \% \mathrm{CO}_{2}$.

Methods. The following biochemical tests were performed according to the procedures outlined in the Virginia Polytechnic Institute and State University Anaerobe Laboratory Manual (3): acetylmethylcarbinol production, arginine hydrolysis, growth in the presence of $2 \%$ oxgall, carbohydrate fermentation, catalase production $\left(0.5 \mathrm{ml}\right.$ of $3 \% \mathrm{H}_{2} \mathrm{O}_{2}$ added to $0.5 \mathrm{ml}$ of a peptone-yeast extract [PY] broth [3] culture containing no hemin), esculin hydrolysis, gas production in PY-glucose agar deeps, gelatin liquefaction, indole production, milk reactions, nitrate reduction, pyruvate utilization, starch hydrolysis, threonine utilization, growth in the presence of Tween 80 , urease production, and volatile and nonvolatile metabolic acid end products. $\mathrm{H}_{2} \mathrm{~S}$ production from $0.3 \%$ L-cysteine was tested by using lead acetate paper. Hemagglutination activity was determined by a slide test, using washed $3 \%$ sheep erythrocytes as described by Slots and Genco (6). The gas chromatograph utilized was a Varian Aerograph series 1400 with a thermal conductivity detector. The column packing in the stainless steel column (length, 6 feet [ca. $1.83 \mathrm{~m}$ ]; diameter, $1 / 1 /$ inch [ca. $3.2 \mathrm{~mm}$ ]) was Supelco 1220 .

The formation of antigen-antibody complexes was determined by an agar gel diffusion method, using $1.2 \%$ agarose (Seakem) in 0.033 ionic strength Veronal buffer, pH 8.6. A satellite pattern well arrangement was utilized (see Fig. 2). Approximately $60 \mu \mathrm{l}$ of unabsorbed, undiluted antiserum was placed in the center well. The peripheral wells each contained $15 \mu \mathrm{l}$ of bacterial sonic extract. Negative controls consisted of normal rabbit sera, which did not produce detectable precipitin bands. Test plates were stored at room temperature in a moist environment for $24 \mathrm{~h}$ before reading.

After the immunization schedule recommended by McCarty and Lancefield (5), antisera specific to the $B$. melaninogenicus strains were prepared by immunizing New Zealand white rabbits against whole, live bacterial cells harvested from Todd-Hewitt broth (BBL) cultures. A 1.0-ml amount of washed bacterial suspension, resuspended into $1 / 10$ the initial volume, was injected via the marginal ear vein on 3 successive days; this was followed by a rest period of 4 days. This immunization schedule was followed for 4 weeks, and then trial bleeding and exsanguination by cardiac puncture were performed.

Bacterial sonic extract was obtained by using a Heat 
Systems model 185 Sonifier (Branson Ultrasonics, Plainview, N.Y.) working at an output of approximately $95 \mathrm{~W}$ and at temperatures ranging from 0 to $10^{\circ} \mathrm{C}$. The bacterial cells were suspended in $0.02 \mathrm{M}$ phosphate-buffered saline, $\mathrm{pH} 7.2$, at a concentration of $100 \mathrm{mg}$ (wet weight) per $\mathrm{ml}$ in a volume of $15 \mathrm{ml}$ and sonicated until $>95 \%$ breakage occurred (approximately 30 min of sonication), as determined by phasecontrast microscopy.

\section{RESULTS}

The six strains examined gave similar results in the tests performed.

Morphology and growth characteristics. The cells were obligately anaerobic, gram negative, nonmotile, nonsporeforming, non-hemagglutinating, coccoid to rod shaped and about 0.5 by 1.0 to $1.5 \mu \mathrm{m}$ in PY-glucose broth cultures and on TSB plates (Fig. 1).

After incubation for 5 days on TSB plates, the colonies were 0.5 to $1.5 \mathrm{~mm}$ in diameter, circular, convex, entire, nonhemolytic, opaque, and grayish-green, turning black with prolonged incubation. The grayish-green shine weakened with repeated subcultivation. The black pigment developed considerably faster on rabbit blood than on sheep blood.

Py-glucose broth cultures were turbid with a smooth sediment. Menadione at $1 \mu \mathrm{g} / \mathrm{ml}$ enhanced growth in PY-glucose broth cultures. Growth was not affected or was only slightly enhanced by the addition of $0.0005 \%$ hemin, $0.3 \%$ formate- $0.3 \%$ fumarate, and $0.02 \%$ Tween 80 . No or negligible growth occurred with $10 \% \mathrm{CO}_{2}$ in air and with $2 \%$ oxgall.

Biochemical characteristics. The biochemical properties of the six strains studied are summarized in Tables 1 and 2. The broth test for $\mathrm{H}_{2} \mathrm{O}_{2}$ decomposition showed a vigorous production of bubbles within $15 \mathrm{~s}$ after the addition

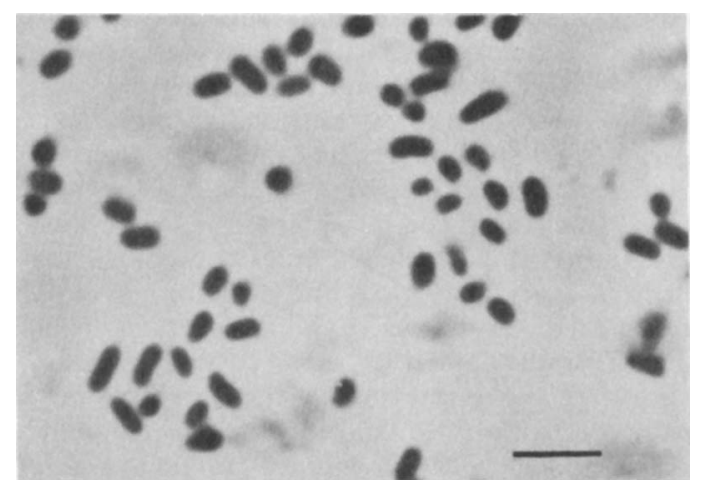

Fig. 1. Monkey strains of $B$. melaninogenicus. Cells from Trypticase soy blood agar were examined in a wet mount preparation by phase-contrast microscopy. Bar $=5 \mu m$.
TABLE 1. Biochemical properties of the monkey strains of $B$. melaninogenicus

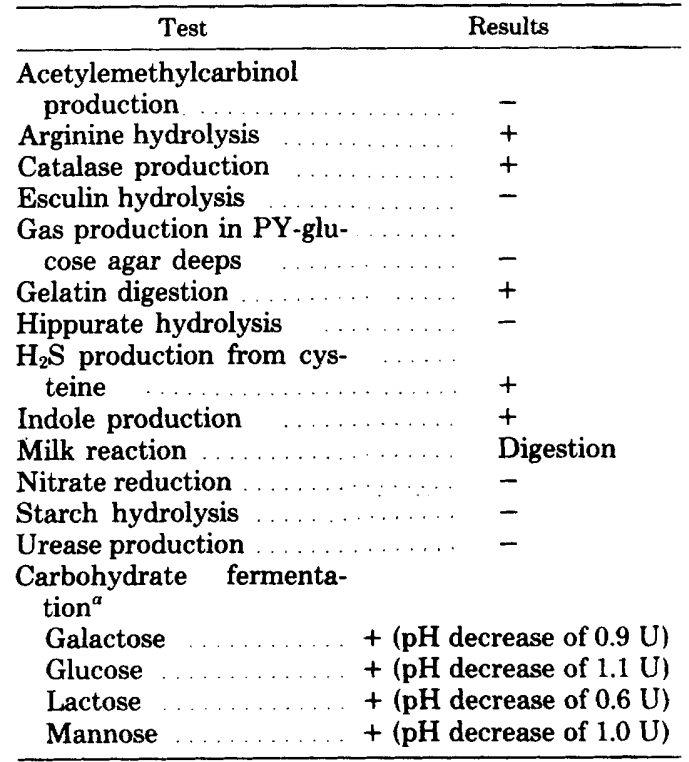

${ }^{a}$ None of the six strains tested produced acid (no $\mathrm{pH}$ decrease $>0.5 \mathrm{U}$ compared with inoculated PY broth [pH 6.9]) from adonitol, amygdalin, arabinose, cellobiose, dextrin, dulcitol, esculin, fructose, glycerol, glycogen, inositol, inulin, maltose, mannitol, melezitose, melibiose, raffinose, rhamnose, ribose, salicin, sorbitol, starch, sucrose, or xylose.

of $\mathrm{H}_{2} \mathrm{O}_{2}$. The $\mathrm{H}_{2} \mathrm{O}_{2}$ decomposition stopped both after the broth culture was heated at $60^{\circ} \mathrm{C}$ for $10 \mathrm{~min}$ and after $5 \mathrm{~min}$ of exposure to $0.001 \mathrm{M}$ (final concentration) potassium cyanide or 0.001 $M$ sodium azide, indicating that the $\mathrm{H}_{2} \mathrm{O}_{2}$ decomposition observed was mediated by a true catalase enzyme (4).

Immunological characteristics. The immunodiffusion test results are shown in Fig 2. Antiserum to strain N.D1-17 formed two major precipitin bands in the homologous reaction when a sonic extract of whole bacterial cells was used. On the other hand, the MD1-17 antiserum formed no detectable precipitates with oral and nonoral strains of $B$. asaccharolyticus and strains of $B$. melaninogenicus subsp. levii, $B$. melaninogenicus subsp. intermedius, and $B$. melaninogenicus subsp. melaninogenicus. Also, sera against the test strains of $B$. asaccharolyticus and $B$. melaninogenicus yielded no line of precipitation with the sonic extract of strain MD1-17. Antiserum to strain MD1-17 reacted with an antigen common to the six monkey strains examined. These data indicate that the six study strains contain unique precipitating antigens. 
TABLE 2. Metabolic acid end products produced by the monkey strains of B. melaninogenicus ${ }^{\prime \prime}$

\begin{tabular}{lccccccc}
\hline \multirow{2}{*}{ Medium } & \multicolumn{5}{c}{ Amt of the following end products (meq/100 ml of medium): } \\
\cline { 2 - 8 } & Acetic acid & Propionic acid Isobutyric acid & Butyric acid Isovaleric acid & Lactic acid & Succinic acid \\
\hline PY & 4.4 & 3.9 & 0.6 & 1.6 & 1.6 & 0 & 0.6 \\
PY-glucose & 6.0 & 6.1 & 0.3 & 0.5 & 0.6 & 0 & 0.5 \\
PY-pyruvate & 4.3 & 3.1 & 0.5 & 0.9 & 1.1 & 0 & 0.5 \\
\hline
\end{tabular}

${ }^{a}$ Pyruvate was utilized (disappearance of pyruvic acid peak in PY-pyruvate broth cultures). Threonine was not converted to propionate.

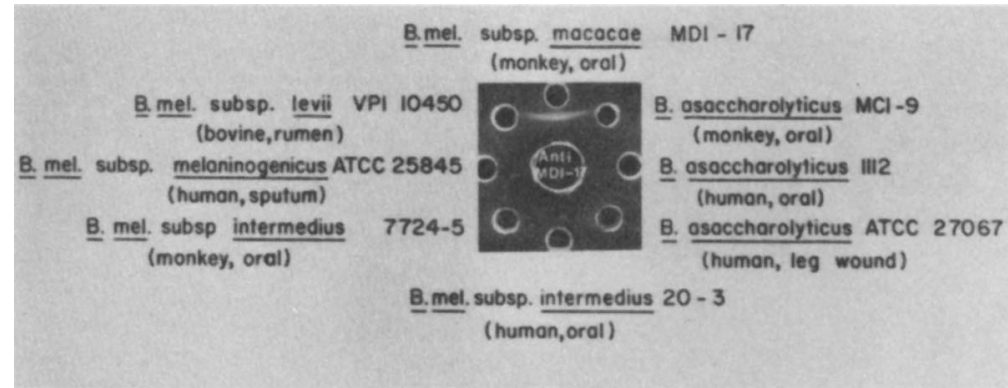

FIG. 2. Immunodiffusion in agar of antigenic components of strain MD1-17, three strains of $B$. asaccharolyticus (MC1-9, 1112, ATCC 27067), two strains of B. melaninogenicus subsp. intermedius (20-3, 7724-5), one strain of B. melaninogenicus subsp. melaninogenicus (ATCC 25845), and one strain of B. melaninogenicus subsp. levii (VPI 10450) against rabbit antiserum to strain MD1-17 (center well). Strain VPI 10450 was from L. V. Holdeman (originally from M. Lev), ATCC 27067 and ATCC 25845 were from the American Type Culture Collection, and MD1-17, MC1-9, 1112, 20-3, and 7724-5 were our own isolates.

\section{DISCUSSION}

The six monkey isolates examined were nonsporulating, gram-negative, anaerobic rods which produced black colonies, characteristics typical of the $B$. asaccharolyticus-B. melaninogenicus group (2). The finding that the monkey strains did ferment galactose, glucose, lactose, and mannose, although weakly, suggests that they are members of $B$. melaninogenicus (2). The monkey strains differ from $B$. asaccharolyticus not only in their fermentation of carbohydrates but also by producing catalase and forming relatively large amounts of acetic and propionic acids in glucose broth cultures. Furthermore, the monkey isolates exhibit no hemagglutination of sheep erythrocytes, in contrast to oral strains of $B$. asaccharolyticus (6). In addition, serological examinations revealed distinct antigenic differences between the monkey strains and the oral and nonoral strains of $B$. asaccharolyticus.

When compared with the three currently recognized subspecies of $B$. melaninogenicus (3), the monkey strains exhibited several phenotypic properties similar to those of $B$. melaninogenicus subsp. levii. They both fail to ferment most carbohydrates and only weakly ferment glucose and lactose. They produce the same acid end products from glucose fermentation, although in differing quantities. Butyric acid and isovaleric acid constitute less than $1 \mathrm{meq} / 100 \mathrm{ml}$ of glucose fermentation medium for the monkey strains and more than $1 \mathrm{meq} / 100 \mathrm{ml}$ for $B$. melaninogenicus subsp. levii (3). The monkey strains also differ from $B$. melaninogenicus subsp. levii by being catalase positive and indole positive and by their antigenic composition.

Major differences exist between the monkey strains and B. melaninogenicus subsp. intermedius and $B$. melaninogenicus subsp. melaninogenicus. For example, strains of these two subspecies fail to produce significant amounts of propionic acid and butyric acid in glucose broth cultures, and they ferment several carbohydrates (3) not fermented by the tested monkey isolates. Distinct antigenic differences also exist between the monkey strains and $B$. melaninogenicus subsp. intermedius and B. melaninogenicus subsp. melaninogenicus.

In conclusion, the monkey strains described here differ physiologically and immunologically from $B$. asaccharolyticus and from the currently recognized subspecies of $B$. melaninogenicus. These strains appear to belong to a new subspecies of $B$. melaninogenicus, for which we propose the name $B$. melaninogenicus subsp. macacae (maća.cae. M. L. fem. n. Macaca generic name of macaque; M. L. gen. n. macacae of macaque). The type strain of this subspecies is 7728-L6C (= American Type Collection strain $33141)$. 


\section{ACKNOWLEDGMENT}

This study was supported in part by Public Health Service grant DE 04898 from the National Institute of Dental Research.

\section{REPRINT REQUESTS}

Address reprint requests to: Dr. Jørgen Slots, Department of Oral Biology, State University of New York at Buffalo, 4510 Main Street, Buffalo, NY 14226.

\section{LITERATURE CITED}

1. Dreizen, S., and B. M. Levy. 1977. Monkey models in dental research. J. Med. Primatol. 6:133-144.

2. Finegold, S. M., and E. M. Barnes. 1977. Report of the ICSB Taxonomic Subcommittee on Gram-Negative Anaerobic Rods. Proposal that the saccharolytic and asaccharolytic strains at present classified in the species Bacteroides melaninogenicus (Oliver and Wherry) be reclassified in two species as Bacteroides melaninogen- icus and Bacteroides asaccharolyticus. Int. J. Syst. Bacteriol. 27:388-391.

3. Holdeman, L. V., E. P. Cato, and W. E. C. Moore (ed.). 1977. Anaerobe laboratory manual, 4th ed. Virginia Polytechnic Institute and State University, Blacksburg.

4. Johnston, M. A., and E. A. Delwiche. 1965. Isolation and characterization of the cyanide-resistant and azideresistant catalase of Lactobacillus plantarum. J. Bacteriol. 90:352-356.

5. McCarty, M., and R. C. Lancefield. 1955. Variation in the group specific carbohydrates of variant strains. $J$. Exp. Med. 102:1-28.

6. Slots, J., and R. J. Genco. 1979. Direct hemagglutination technique for differentiating Bacteroides asaccharolyticus oral strains from nonoral strains. J. Clin. Microbiol. 10:371-373.

7. Slots, J., and E. Hausmann. 1979. Longitudinal study of experimentally induced periodontal disease in $\mathrm{Ma}$. caca arctoides: relationship between microflora and alveolar bone loss. Infect. Immun. 23:260-269. 